\title{
Location Tracking Using Bluetooth iTag
}

\author{
Joseph Dedy Irawan ${ }^{\mathrm{a}, 1,{ }^{*}}$, Yudi Limpraptono ${ }^{\mathrm{b}, 2}$, Emmalia Adriantantri ${ }^{\mathrm{b}, 3}$ \\ ${ }^{a 1}$ National Institute of Technology Malang-Informatic Program, Jl. Sigura-Gura No.2, Sumbersari, Malang and 65152, \\ Indonesia \\ b2 National Institute of Technology Malang-Electrical Engineering Program, J1. Sigura-Gura No.2, Sumbersari, Malang \\ and 65152 , Indonesia

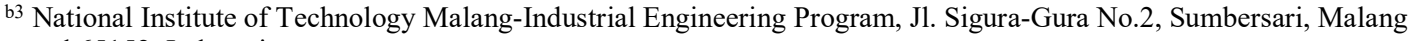 \\ and 65152 , Indonesia \\ ${ }^{1}$ joseph@lecture.itn.ac.id*; ${ }^{2}$ fyudi1@lecture.itn.ac.id; ${ }^{3}$ emmalia@lecture.itn.ac.id
}

\begin{tabular}{|c|c|}
\hline & ABSTRACT \\
\hline $\begin{array}{l}\text { Keywords } \\
\text { Bluetooth iTag } \\
\text { Locatiaon Tracking }\end{array}$ & $\begin{array}{l}\text { Abstract Bluetooth iTag is an electronic technology development, particularly in the field } \\
\text { of data communication between devices. In this study, a keychain that can communicate } \\
\text { with other devices uses Bluetooth communication for location tracking and searching for } \\
\text { lost items. Developing an application to determine this location starts with the connection } \\
\text { to a Bluetooth device and continues by determining the location of the Bluetooth iTag. } \\
\text { After tracking the location, this application can be further developed as several other } \\
\text { applications, such as searching for lost items, monitoring the locations of young children } \\
\text { and pets and other applications. }\end{array}$ \\
\hline
\end{tabular}

\section{Introduction}

Determinating location at the present time is usually done with the help of the Global Positioning System (GPS). Using satellites, position can be determined accurately, but using GPS in an indoor location is disrupted because the device does not receive signals from satellites to determine location. To address this problem, another device was developed that aims to determine location by utilizing Bluetooth Low Energy (BLE) technology, which involves a location search process using GPS, but the communication used is Bluetooth.

By using Bluetooth communication, computer devices and gadgets can easily be connected to these devices. Then, by creating an application that will later be embedded in a smartphone, an application can be used to determine location using the Bluetooth iTag device. It is expected that this application can be useful in various ways, including searching for lost objects, monitoring the location of small children when we travel, monitoring the location of pets, and other needs for tracking location.

\section{Method}

Bluetooth Low Energy (BLE) is a communication technology between electronic devices that requires low power. Developed for short-distance control and monitoring applications [1]-[3], this communication device can function as a wireless network and can be used for a variety of applications. Its advantages in regard to low power usage compared to earlier Bluetooth technology include reducing the ability to communicate and range distance.

Today, almost all electronic devices utilize BLE as a data communication medium. It is used, for example, in the automotive industry [4], for medical equipment [5], [6], in social interaction [7], and in the world of entertainment [8], [9], and for location tracking [10], [11], indoors using BLE beacons with a fairly high degree of accuracy [12], [13]. Other than that, communication using this device for data communication that is large enough can run well [14]. Therefore, in this study, an application

91 I $\mathrm{P}$ a g e 
will be developed that can perform location tracking with Bluetooth iTags that can be used to search for lost items and for monitoring the location of young children and pets.

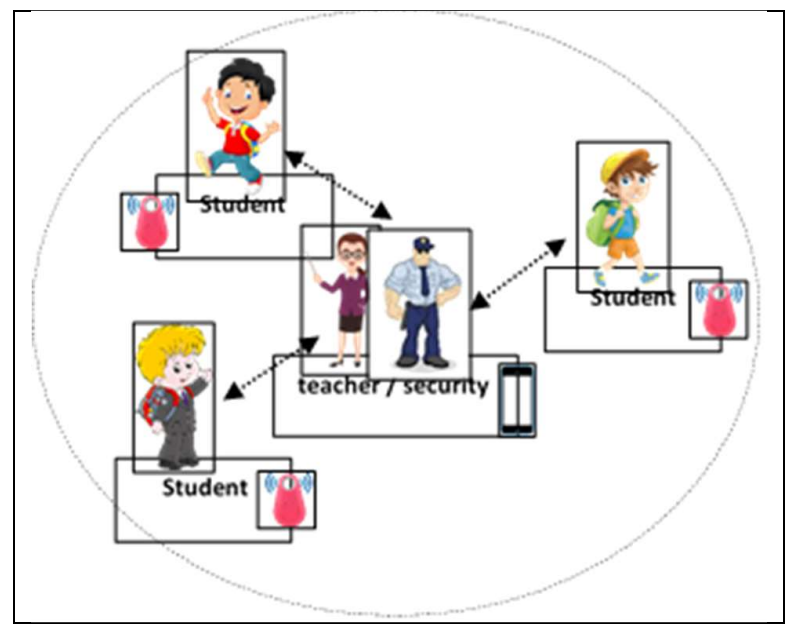

Fig. 1.Blog Diagram System

One implementation of Bluetooth iTag location tracking in everyday life is tracking the location of children. Figure 1 illustrates a system whereby a teacher or a security system can monitor the location of a child within certain areas. Every child monitored carries a Bluetooth iTag with a different ID number for each device, while the teacher or other security personnel uses a smartphone equipped with an application designed to supervise students. For example, a monitoring area of 15 meters might be set; if any student is more than 15 meters away, the application will automatically send a notification to the teacher's smartphone and other security personnel so that action can be taken to prevent the child from leaving the monitored area.

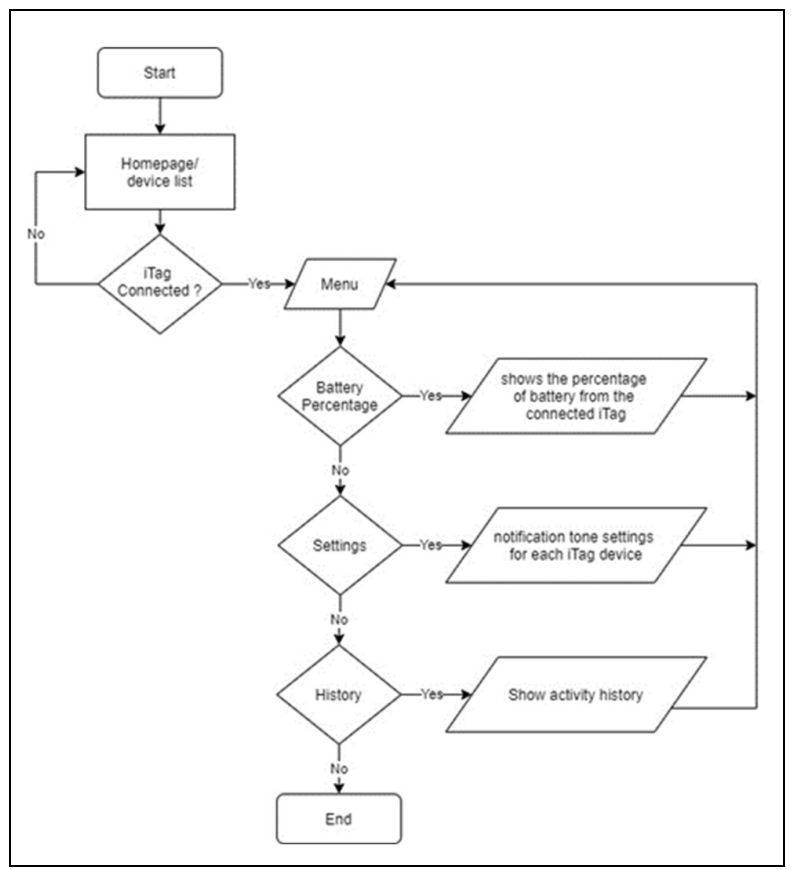

Fig. 2.Flowchart Setting

When the application is run, several settings need to be made, starting with searching for Bluetooth iTags that can connect to the application. If there is a Bluetooth iTag connected, it will include the student's name because each student will have one iTag. This will be followed by settings for notification tones that aim to distinguish one type of notification from another. The application can 
also show the percentage of battery power from each iTag so that it can be immediately replaced if the power is very low. In addition, activity history can be displayed in this application.

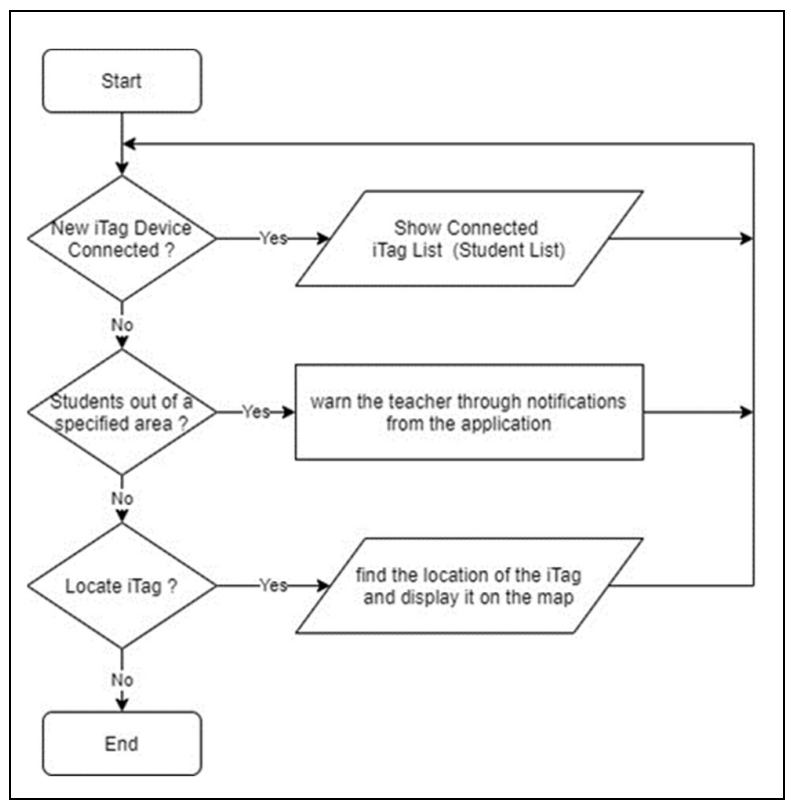

Fig. 3.Flowchart System

After performing the settings, the application will continuously search for new Bluetooth iTag devices that can be connected. If there is a new Bluetooth iTag-connected, it will appear on the list of connected iTags. If there are students who leave the monitored area, then the application will automatically notify the teacher or security personnel. In addition, the teacher can find the locations of various students and display these on the map.

\section{Results and Discussion}

When the application is run, it will display a list of detected Bluetooth iTags. Each iTag will represent a student because each student will carry an iTag. Based on this list, students can be monitored by the teacher or security camera or personnel. If a student leaves the monitored area, the Bluetooth iTag automatically emits an alarm sound as well as applications run by the teacher, and security will provide a notification sound so that the student who is out of the surveillance area is quickly identified and action can be taken immediately. 


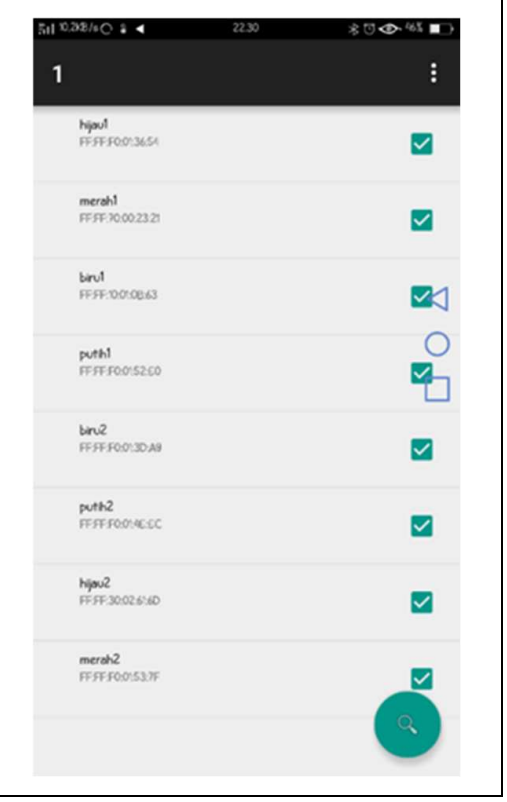

Fig. 4. Bluetooth iTag List

To distinguish each student on the list, the sound settings menu can be used to set a different alarm sound for each child. Figure 5 shows what alarm sound settings will be sounded if the child exits the monitored area as well as other alarms.

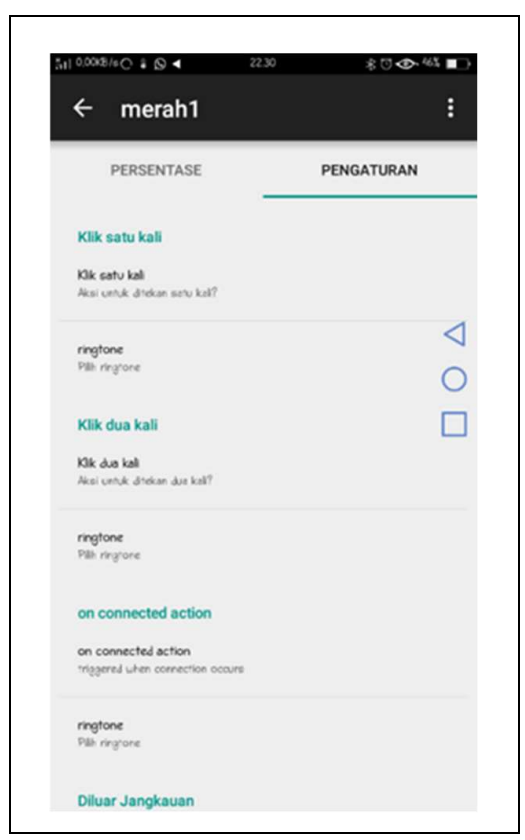

Fig. 5. Notification Setting

To determine the child's exact location, the teacher or security personnel presses the location button for the student. The application will provide location information in the form of longitude and latitude coordinates from the Bluetooth iTag and display it on the map. Figure 6 shows location setting. 


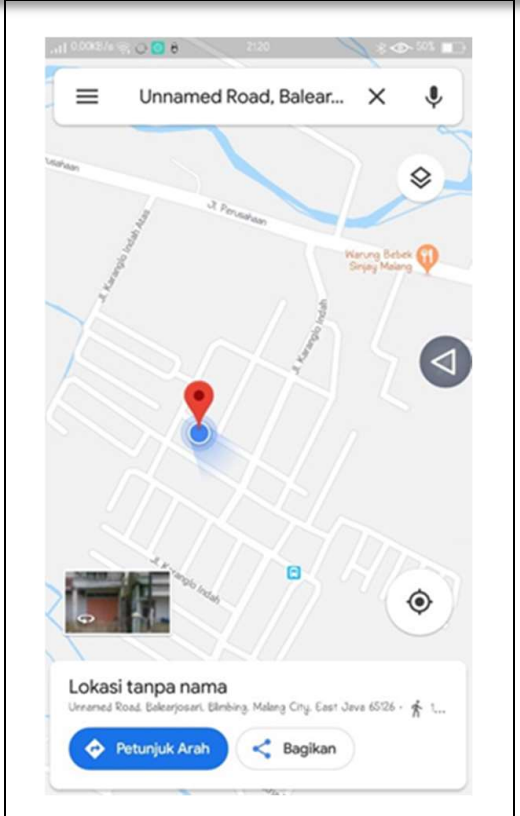

Fig. 6.Location Setting

Table 1. Bluetooth iTag Range Testing

\begin{tabular}{cccc}
\multirow{2}{*}{$\begin{array}{c}\text { Distance } \\
\text { (meter) }\end{array}$} & Activity & Result & \\
\cline { 3 - 4 } 15 & Vibrates & $\checkmark$ & Failed \\
\hline \multirow{4}{*}{ Ring } & $\checkmark$ & \\
& Located & $\checkmark$ & \\
\hline \multirow{2}{*}{20} & Vibrates & $\checkmark$ & \\
& Ring & $\checkmark$ & \\
& Located & $\checkmark$ & \\
\hline \multirow{5}{*}{23} & Vibrates & $\checkmark$ & \\
& Ring & $\checkmark$ & \\
& Located & $\checkmark$ & $\checkmark$ \\
25 & Vibrates & & $\checkmark$ \\
& Ring & & $\checkmark$ \\
\hline
\end{tabular}

Based on distance testing, it was found that the maximum distance from an iTag to be able to communicate properly is 23 meters. At this distance, the button pressed on the iTag can be detected by the application on the smartphone, and the button pressed on the phone can be received by the iTag by sounding the speaker inside.

\section{Conclusion}

From the test results, it can be concluded that the connection between a Bluetooth iTag and a smartphone for performing various actions is more accurate outside than indoors. We noted only 5 successful actions performed indoors, while 9 successful actions were performed outdoors. In the second test conducted at a distance of 23 meters outside, sending locations from Bluetooth iTag to smartphones held by supervisors experienced an average delay of 5-7 seconds per action. 


\section{References}

[1] S. Kamath and J. Lindh, "Measuring bluetooth low energy power consumption," Texas instruments Appl. note AN092, Dallas, 2010.

[2] C. Gomez, J. Oller, and J. Paradells, "Overview and evaluation of bluetooth low energy: An emerging low-power wireless technology," Sensors, vol. 12, no. 9, pp. 11734-11753, 2012.

[3] E. Mackensen, M. Lai, and T. M. Wendt, "Bluetooth Low Energy (BLE) based wireless sensors," in SENSORS, 2012 IEEE, 2012, pp. 1-4.

[4] N. R. Gautama, A. J. Kalhous, R. A. Hrabak, and N. J. Weigert, "Method and system for detecting proximity of an end device to a vehicle based on signal strength information received over a bluetooth low energy (BLE) advertising channel." Google Patents, Apr. 14, 2015.

[5] I. Ahmed, H. Karvonen, T. Kumpuniemi, and M. Katz, "Wireless Communications for the Hospital of the Future: Requirements, Challenges and Solutions," Int. J. Wirel. Inf. Networks, vol. 27, no. 1, pp. 4-17, 2020.

[6] A. F. Hussein, S. J. Hashim, A. F. A. Aziz, F. Z. Rokhani, and W. A. W. Adnan, "A real time ECG data compression scheme for enhanced bluetooth low energy ECG system power consumption," J. Ambient Intell. Humaniz. Comput., pp. 1-14, 2017.

[7] P. Baronti, P. Barsocchi, S. Chessa, F. Mavilia, and F. Palumbo, "Indoor Bluetooth low energy dataset for localization, tracking, occupancy, and social interaction," Sensors, vol. 18, no. 12, p. 4462, 2018.

[8] G. Panwar and S. Misra, "Inside Bluetooth Low Energy (Gupta, N.)[Book Review]," IEEE Wirel. Commun., vol. 24, no. 4, pp. 2-3, 2017.

[9] Y. Tsuchida, "Car entertainment control system.” Google Patents, Jul. 20, 2017.

[10] Y. Zhuang, J. Yang, Y. Li, L. Qi, and N. El-Sheimy, "Smartphone-based indoor localization with bluetooth low energy beacons," Sensors, vol. 16, no. 5, p. 596, 2016.

[11] F. Palumbo, P. Barsocchi, S. Chessa, and J. C. Augusto, "A stigmergic approach to indoor localization using bluetooth low energy beacons," in 2015 12th IEEE International Conference on Advanced Video and Signal Based Surveillance (AVSS), 2015, pp. 1-6.

[12] P. Kriz, F. Maly, and T. Kozel, "Improving indoor localization using bluetooth low energy beacons," Mob. Inf. Syst., vol. 2016, 2016.

[13] R. Faragher and R. Harle, "An Analysis of the Accuracy of Bluetooth Low Energy for Indoor Positioning Applications.(2014)," Dostopno na http//www. cl. cam. ac. uk/ rmf25/papers/BLE. pdf [15. 7. 2016], 2014.

[14] J. A. Afonso, A. J. F. Maio, and R. Simoes, "Performance evaluation of bluetooth low energy for high data rate body area networks," Wirel. Pers. Commun., vol. 90, no. 1, pp. 121-141, 2016. 